\title{
Inland post-glacial dispersal in East Asia revealed by mitochondrial haplogroup M9a'b
}

\author{
Min-Sheng Peng ${ }^{1,2,6}$, Malliya Gounder Palanichamy ${ }^{3}$, Yong-Gang Yao ${ }^{4}$, Bikash Mitra ${ }^{3,5}$, Yao-Ting Cheng ${ }^{1,2,6}$, \\ Mian Zhao 1,2,6, Jia Liu ${ }^{3}$, Hua-Wei Wang ${ }^{3}$, Hui Pan ${ }^{1,2,6}$, Wen-Zhi Wang ${ }^{1,2,6}$, A-Mei Zhang ${ }^{4,6}$, Wen Zhang ${ }^{4,6}$, \\ Dong Wang ${ }^{4,6}$, Yang Zou ${ }^{4,6}$, Yang Yang ${ }^{3}$, Tapas Kumar Chaudhuri ${ }^{5}$, Qing-Peng Kong ${ }^{1,2^{*}}$, Ya-Ping Zhang ${ }^{1,2,3^{*}}$
}

\begin{abstract}
Background: Archaeological studies have revealed a series of cultural changes around the Last Glacial Maximum in East Asia; whether these changes left any signatures in the gene pool of East Asians remains poorly indicated. To achieve deeper insights into the demographic history of modern humans in East Asia around the Last Glacial Maximum, we extensively analyzed mitochondrial DNA haplogroup M9a'b, a specific haplogroup that was suggested to have some potential for tracing the migration around the Last Glacial Maximum in East Eurasia.

Results: A total of 837 M9a'b mitochondrial DNAs (583 from the literature, while the remaining 254 were newly collected in this study) pinpointed from over 28,000 subjects residing across East Eurasia were studied here. Fiftynine representative samples were further selected for total mitochondrial DNA sequencing so we could better understand the phylogeny within M9a'b. Based on the updated phylogeny, an extensive phylogeographic analysis was carried out to reveal the differentiation of haplogroup M9a'b and to reconstruct the dispersal histories.

Conclusions: Our results indicated that southern China and/or Southeast Asia likely served as the source of some post-Last Glacial Maximum dispersal(s). The detailed dissection of haplogroup M9a'b revealed the existence of an inland dispersal in mainland East Asia during the post-glacial period. It was this dispersal that expanded not only to western China but also to northeast India and the south Himalaya region. A similar phylogeographic distribution pattern was also observed for haplogroup F1c, thus substantiating our proposition. This inland post-glacial dispersal was in agreement with the spread of the Mesolithic culture originating in South China and northern Vietnam.
\end{abstract}

\section{Background}

The climatic oscillation and the related ecological changes around the Last Glacial Maximum (LGM; approximately 26.5 to 19 kilo-years ago (kya)) [1] were suggested to exert substantial influence on prehistoric migrations and demographic changes in modern humans [2]. In East Asia, archaeological studies have indicated that great changes occurred in the wake of the LGM [3,4]. For instance, the microblade technology appeared and became popular during the LGM in northern China [5]; some early settlements were abandoned [6] and people probably moved to the south due to the deteriorating environmental conditions [7]. After the LGM, improved climate allowed humans to

\footnotetext{
* Correspondence: kongqp@yahoo.com.cn; zhangyp@mail.kiz.ac.cn

'State Key Laboratory of Genetic Resources and Evolution, Kunming Institute of Zoology, Chinese Academy of Sciences, Kunming, China

Full list of author information is available at the end of the article
}

re-colonize the high latitude regions [8]. However, whether the ancient dispersals around the LGM left any detectable genetic footprints in the gene pool of the contemporary East Asians was still elusive.

In the past decades, genetic data of mitochondrial DNA (mtDNA) and the non-recombining region of Y-chromosome (NRY) have been widely employed to reconstruct human prehistory $[9,10]$. In Europe, the detailed phylogeographic dissection of matrilineal pools has discerned some haplogroups as the candidate markers for tracing the dispersal(s) after the LGM, which could be assigned as the Late Glacial (before the Holocene) and the postglacial (after the Younger Dryas but before the Neolithic) re-colonization, respectively [11]. Recently, this strategy has also been applied to other regions (for example, West Asia [12], South Asia [13], and Southeast Asia [14]), yielding many valuable insights into the prehistoric demographic events around the LGM.

\section{() Biomed Central}

(c) 2011 Peng et al; licensee BioMed Central Ltd. This is an Open Access article distributed under the terms of the Creative Commons Attribution License (http://creativecommons.org/licenses/by/2.0), which permits unrestricted use, distribution, and reproduction in any medium, provided the original work is properly cited. 
To trace the ancient dispersal of modern humans in East Asia around the LGM, we carried out a detailed phylogeographic analysis on a high resolution mtDNA marker. We focused our attention particularly on East Eurasian specific mtDNA haplogroup M9a'b for four reasons: 1) M9a'b distributes widely in mainland East Asia [14] and is relatively concentrated in Tibet (approximately 19.2\%) [15,16] and its surrounding regions, including Nepal (approximately 11.6\%) [17], Sikkim (approximately 11.7\%) [18] and northeast India (approximately $8.6 \%$ ) $[18,19]$. 2) The phylogeny of haplogroup M9a'b indicated that this clade might be involved in some northward migrations into East Asia from Southeast Asia [14]. 3) The coalescent time estimates of certain sub-haplogroups of M9a'b, for example, M9a (approximately 12 to 15 kya) [14,16] and M9d (approximately 12 kya) [16], suggested that these lineages were likely associated with some post-LGM dispersal(s) in East Asia [14], especially in Tibet $[15,16] .4)$ In addition to its high frequency, the relatively high genetic diversity, as revealed by the mtDNA control region hypervariable segment I (HVS-I) information in Tibet [20], suggested that Tibet might serve as the potential differentiation center of M9a'b sub-haplogroups. All these lines of evidence appeared to imply that Tibet might be a candidate source for the post-LGM dispersal in East Asia. Together, the detailed dissection of haplogroup M9a'b would provide insightful information for the ancient movement of modern humans in East Asia around the LGM.

\section{Results \\ M9a'b phylogenetic tree based on mtDNA genome information}

After incorporating the 59 newly sequenced mtDNA genomes, the phylogeny of haplogroup M9a'b was greatly improved in the context of East Eurasians (Figure 1). The overall structure of the tree turned out to be much more complex than we had ever thought [14-16,18,20,21] (Figure 2). For instance, a number of basal lineages branched directly from the M9a'b root and shared merely two variants 16234 and 14308 with previously defined haplogroups M9a and M9d [16,18]. To update the definitions of haplogroup M9a'b and its sub-haplogroups and to avoid potential confusion, we kept the definition of M9a'b, but expanded that of M9a (now defined by transitions 14308 and 16234) to embrace M9a1 (defined by variant 1041), M9a4 (defined by transition 6366), and M9a5 (determined by variants 385,8155 , and 12237). Nomenclature of some other sub-haplogroups, such as M9a1b (former M9d $[16,18]$ ), M9a1a1 (former M9a [18]), and M9a1a2 (former M9e [16]), were adjusted accordingly (Figure 2).
It should be mentioned that although the validity of M9a1a might be questionable because this haplogroup was defined solely by a control region variation at site 16316, its two major clades (M9a1a1 and M9a1a2) were determined by additional coding region variants. The updated nomenclature has been deposited to PhyloTree (http://www.phylotree.org, mtDNA tree Build 10) [22].

Based on the updated M9a'b phylogeny, some interesting features could be discerned. With the exception of M9a1, most basal branches of M9a were distributed in southern China (6/15) and Southeast Asia (7/15); this pattern suggested that M9a might have a southern origin. The distribution pattern of M9a1 was rather complex: although this haplogroup did bear some genetic imprints of southern origin by harboring a basal lineage (that is, $H N-H H 27$ ) from southern China, its effect had actually extended to northern China and Japan (for example, M9a1a1a, M9a1a1b, and M9a1a1c1a), as well as, western China (that is, southwestern China, northwestern China, and Tibet), northeast India (including Bangladesh), and the south Himalaya region (for example, M9a1b1, M9a1a2, and M9a1a1c1b). Based on this pattern, it seemed that haplogroup M9a1 had most likely been involved in some northward and westward dispersal(s) in East Asia.

\section{Phylogeographic distribution}

The updated phylogenetic tree of haplogroup M9a'b provided a basis for us to reanalyze the previously published data and to perform a well-defined phylogeographic analysis of this haplogroup. To better characterize the demographic history of M9a'b, the median-joining network was constructed based on all available M9a'b mtDNAs (Figure 3 ). In general, the network (based on the combined information of the control region and partial coding region) was in agreement with the phylogeny of the entire mtDNA genomes (Figure 2). Our comprehensive study of haplogroup M9a'b substantiated the notion that the origin of this haplogroup was most likely located in southern China and/or mainland Southeast Asia. As displayed in Figure 3, most of the basal lineages within M9a (that is, M9a"; excluding M9a1a and M9a1b mtDNAs) came from southern China, southwestern China, and Southeast Asia, strongly suggesting a southern origin of M9a. This result received further support from M9b: 9 of the $11 \mathrm{M} 9 \mathrm{~b}$ sequences were observed in southern China, southwestern China, and Southeast Asia, while the remaining two were found in northwestern China and northern China, respectively (Figure 3; see Additional file 1).

Similar to the observation from the phylogenetic tree of the complete mtDNAs (Figure 2), the median-network showed that the dominant clade (M9a1) within M9a presented a quite different geographic distribution pattern from its sister cluster M9a* (Figure 3). Within 


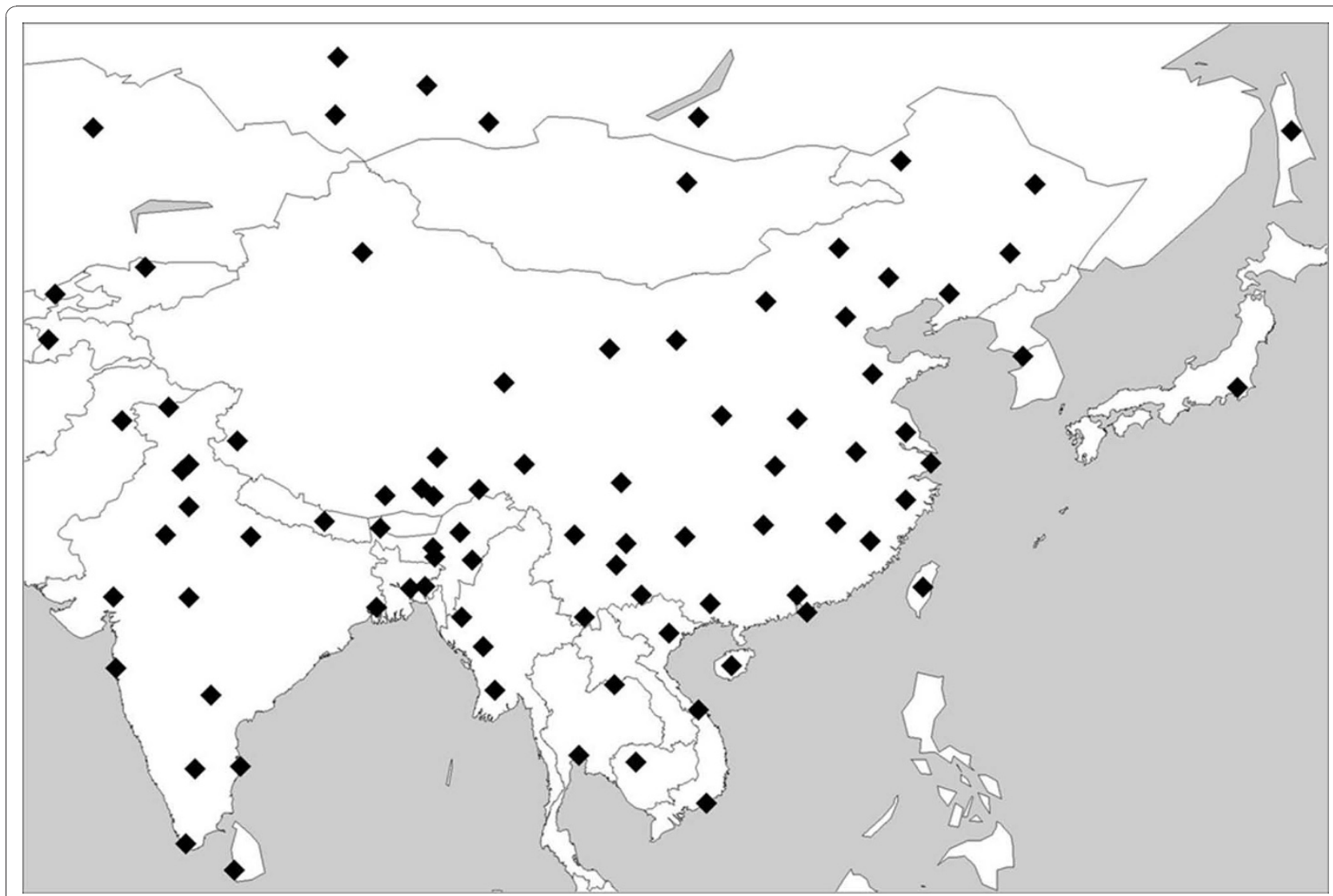

Figure 1 Geographic locations of populations surveyed in this study. For more details regarding the populations, refer to Additional file 2 .

haplogroup M9a1b, the basal lineages were mainly restricted to western China and Myanmar, whereas M9a1b1 spread not only in western China and Myanmar, but also in northeast India and the south Himalaya region (Figure 3). The basal lineages belonging to M9a1a* were mainly found in southern China (Figure 3). One of its derivatives, haplogroup M9a1a2, displayed a restricted distribution in western China, Myanmar, northeast India, and the south Himalaya region (Figure 3 and 4; see Additional file 2), and presented a similar pattern to that of haplogroup M9a1b1. Nevertheless, haplogroup M9a1a1 showed a distinct distribution pattern: most of M9a1a1 basal lineages were distributed in southern China, southwestern China, as well as, northern China, Japan and Korea, whereas its major sub-haplogroup M9a1a1c was prevalent in northern China, Korea, and Japan (Figure 3 and 4; see Additional file 2). Remarkably, the M9a1a1 lineages found in Tibet were almost clustered into haplogroup M9a1a1c1b.

\section{Coalescence age estimates}

The large number of M9a'b samples with complete mtDNA genome information, as well as the network with a high-resolution, allowed us to estimate the coalescence ages of the nodes (viz., ancestral haplotypes within M9a'b) of interest. Although there were some exceptions, the estimated ages based on different calibrated rates were in general accordance with each other and seemed to be quite robust (Table 1). The whole haplogroup M9a'b showed a coalescence time of approximately 26 to $28 \mathrm{kya}$. The estimated coalescence age of haplogroup M9a was approximately 18 to 23 kya. Within haplogroup M9a1, haplogroups M9a1a1 and M9a1b1 emerged around 14 to 17 kya and 9 to 12 kya, respectively. For haplogroup M9a1a2, because of the small number of available mtDNA genome sequences, which would bias the age estimates, we adopted the age estimation result based on HVS-I data $(11.3 \pm 3.5 \mathrm{kya})$. As a result, nearly all the age estimates placed the origin of haplogroup M9a1a1 in the Late Glacial episode, whereas haplogroups M9a1b1 and M9a1a2 are in a more recent post-glacial period (the end of the Pleistocene and the early Holocene), despite a fact that these ages should be received with caution $[23,24]$.

\section{Discussion}

Although some previous studies based on limited information from mtDNA control region suggested that 

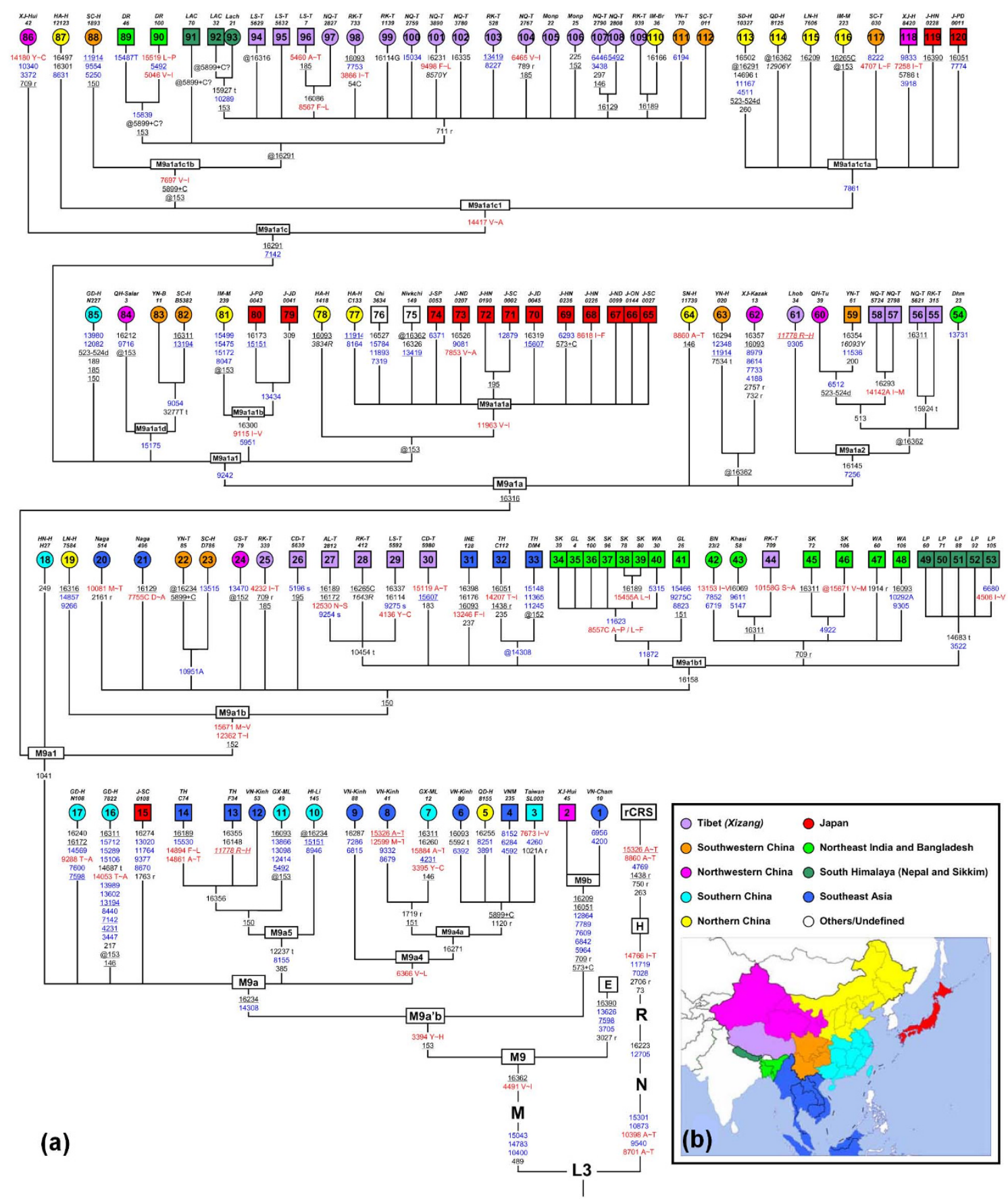

Figure 2 Classification tree of $\mathbf{M} 9 \mathbf{a}^{\prime} \mathbf{b}$ rooted in haplogroup $\mathbf{M 9}$. (a) The tree includes 120 complete sequences and illustrates subhaplogroup affiliations (see Additional file 4). Sequences 1, 5 to 12,16 to 25,42 to $43,54,60$ to 64,77 to 78,81 to $88,93,97$ to 117 were newly collected and indicated as circles, while the others from published sources were represented as squares. The nucleotide positions in the sequences were scored relative to the revised Cambridge Reference Sequence ( $r$ CRS) [52]. Transitions are shown on the branches and transversions are further annotated by adding suffixes. The deletions and insertions are demonstrated by " $d$ " and " + ", respectively. Amino acid replacements are in red and marked by a single-letter code, whereas synonymous replacements are in blue. Changes in transfer RNA and ribosomal RNA genes are denoted by " $\mathrm{t}$ " and " $r$ ", respectively. The prefix @ designates back mutation and recurrent variants are underlined. "R" and " $Y$ " specify the heteroplasmic status of $A / G$ and $C / T$ at a certain site, respectively. All heteroplasmic variants and the potential pathogenic transition 11778 [62] are not considered in the ages estimates and are marked in italics. The insertion of C at site 5899 seemed to be missing in sequences 88 to 91, which is tentatively noted as "@5899+C?". (b) The geographic origin of samples is shown by different colors corresponding to their respective different locations in the map. 


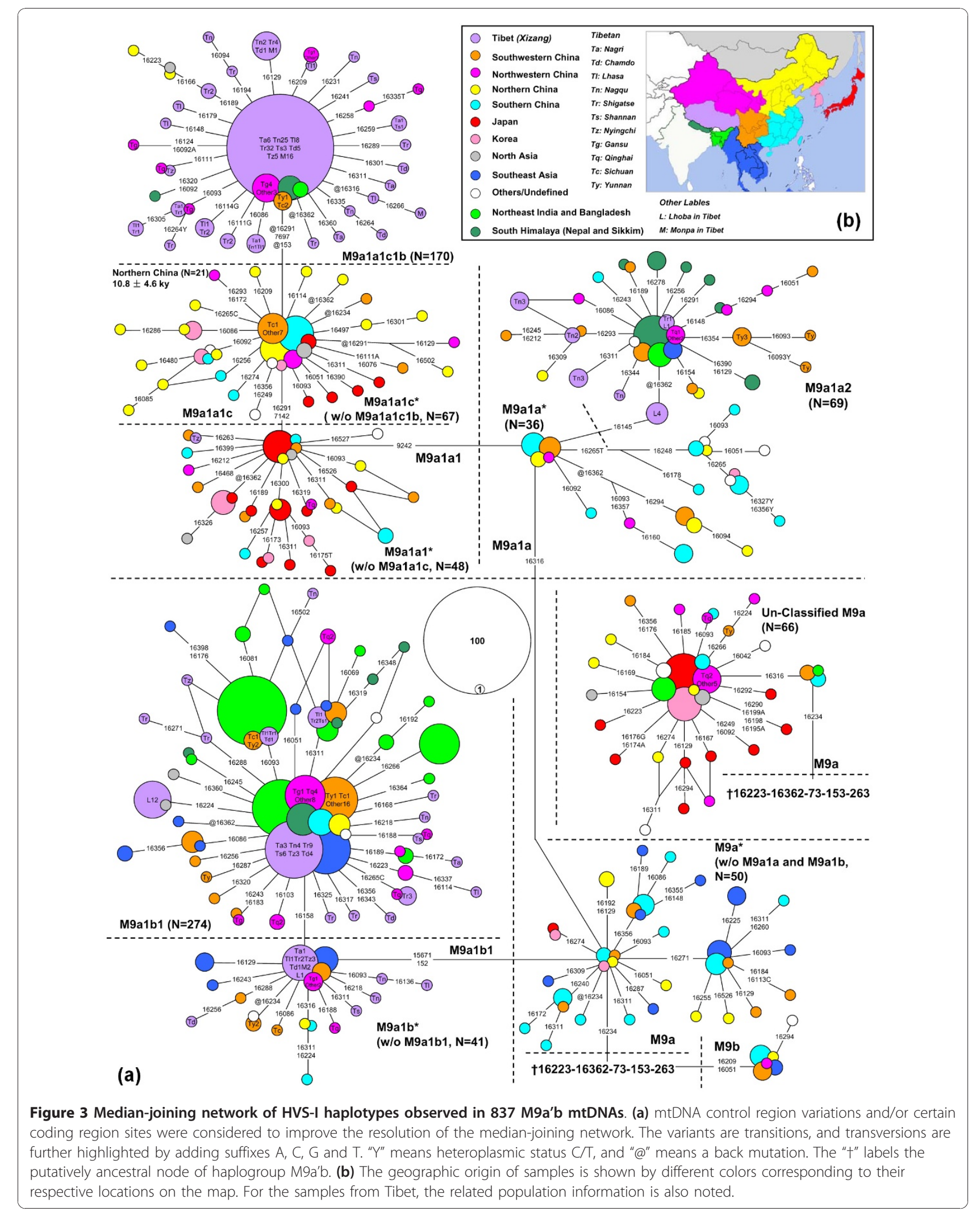



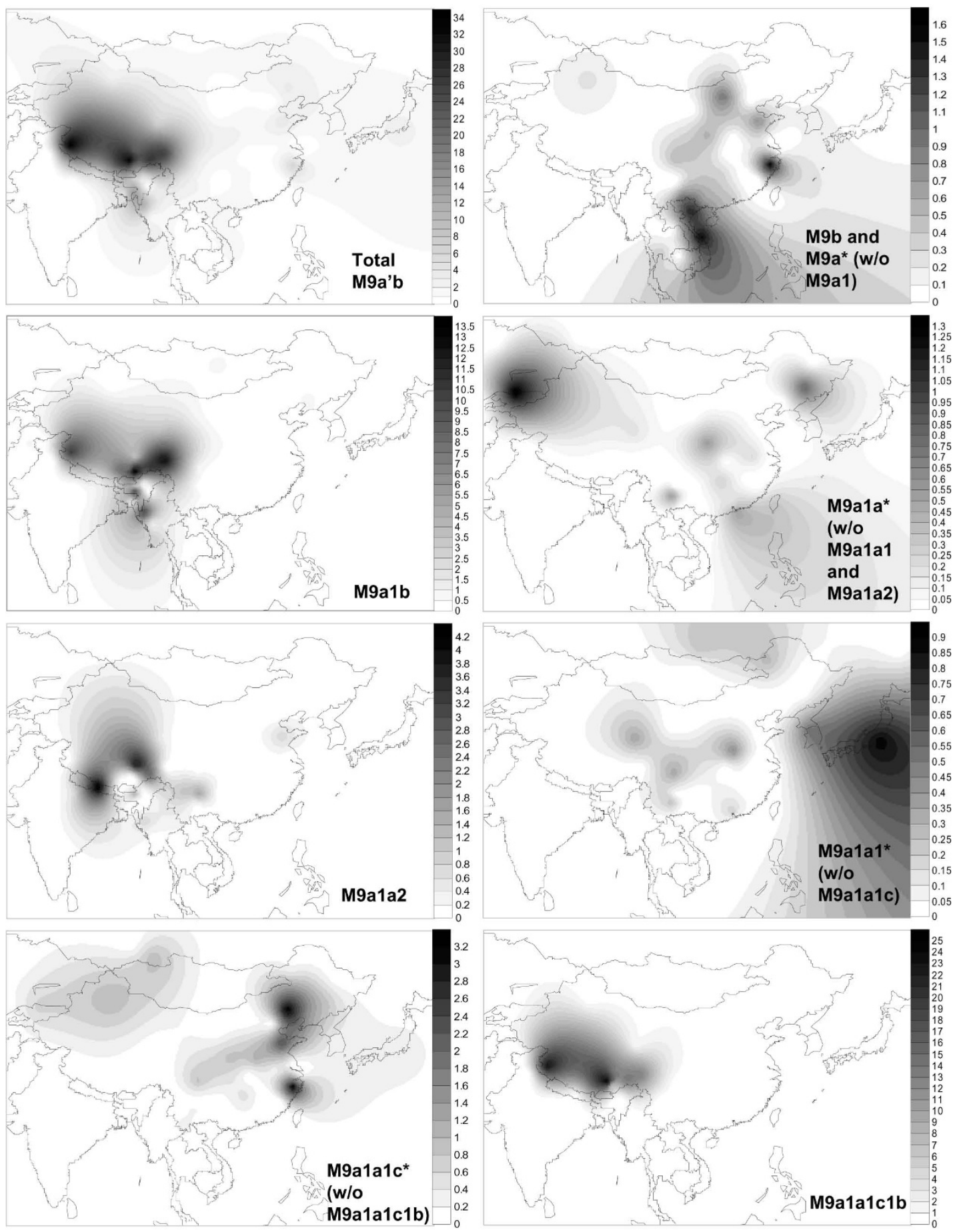

Figure 4 Spatial frequency distributions of haplogroup M9a'b and its sub-haplogroups. Populations and corresponding frequency values are listed in Additional file 2. Fifty mtDNAs were not included in computing the population frequency because the essential information was missing or not reported in the original studies (see Additional file 1). The spatial-frequency distributions were created using the Kriging algorithm of the Surfer 8.0 package. 
Table 1 Estimated coalescence ages of mtDNA haplogroup M9a'b and its sub-haplogroups based on different calibration rates

\begin{tabular}{|c|c|c|c|c|c|c|c|c|c|c|c|c|c|c|}
\hline \multirow[b]{2}{*}{ Node/Clade } & \multirow[b]{2}{*}{$\mathrm{N}^{\mathrm{a}}$} & \multicolumn{4}{|c|}{ Entire mitochondrial genome } & \multicolumn{4}{|c|}{ Only synonymous mutations } & \multirow[b]{2}{*}{$\mathrm{N}^{\mathrm{a}}$} & \multicolumn{4}{|c|}{ Transitions in 16090 to 16365} \\
\hline & & $\rho$ & $\sigma$ & $\mathrm{T}^{\mathrm{b}}(\mathrm{ky})$ & $\Delta \mathrm{T}^{\mathrm{b}}(\mathrm{ky})$ & $\rho$ & $\sigma$ & $\mathrm{T}^{\mathrm{c}}(\mathrm{ky})$ & $\Delta T^{c}(k y)$ & & $\rho$ & $\sigma$ & $T^{d}(k y)$ & $\Delta \mathrm{T}^{\mathrm{d}}(\mathrm{ky})$ \\
\hline M9a'b & 120 & 10.83 & 2.01 & 28.0 & 5.2 & 3.28 & 1.14 & 26.2 & 9.1 & & & & & \\
\hline M9a & 118 & 8.86 & 1.48 & 22.9 & 3.8 & 2.23 & 0.59 & 17.8 & 4.7 & & & & & \\
\hline M9a* (w/o M9a1) & 15 & 7.40 & 1.11 & 19.1 & 2.9 & 2.73 & 0.52 & 21.8 & 4.2 & 50 & 1.20 & 0.46 & 22.6 & 8.7 \\
\hline M9a5 & 5 & 4.40 & 1.26 & 11.4 & 3.3 & 1.40 & 0.53 & 11.2 & 4.2 & & & & & \\
\hline M9a4 & 7 & 5.57 & 1.32 & 14.4 & 3.4 & 1.71 & 0.49 & 13.7 & 4.0 & & & & & \\
\hline M9a1 & 103 & 8.07 & 1.36 & 20.9 & 3.5 & 2.16 & 0.67 & 17.2 & 5.3 & & & & & \\
\hline M9a1b & 35 & 5.03 & 1.35 & 13.0 & 3.5 & 1.37 & 0.37 & 11.0 & 3.0 & & & & & \\
\hline M9a1b* (w/o M9a1b1) & 8 & 3.13 & 1.04 & 8.1 & 2.7 & 0.88 & 0.38 & 7.0 & 3.0 & 41 & 0.51 & 0.16 & 9.7 & 3.0 \\
\hline M9a1b1 & 27 & 3.59 & 0.68 & 9.3 & 1.8 & 1.52 & 0.47 & 12.1 & 3.8 & 274 & 0.55 & 0.23 & 10.5 & 4.3 \\
\hline M9a1a & 67 & 7.19 & 1.43 & 18.6 & 3.7 & 2.60 & 1.01 & 20.8 & 8.1 & & & & & \\
\hline M9a1a2 & 8 & 3.13 & 1.17 & 8.1 & 3.0 & 0.63 & 0.33 & 5.0 & 2.6 & $65^{e}$ & 0.60 & 0.19 & 11.3 & 3.5 \\
\hline M9a1a1 & 56 & 6.59 & 1.37 & 17.0 & 3.5 & 1.77 & 0.66 & 14.1 & 5.3 & & & & & \\
\hline M9a1a1* (w/o M9a1a1c) & 21 & 4.00 & 1.01 & 10.3 & 2.6 & 1.43 & 0.32 & 11.4 & 2.6 & 48 & 0.77 & 0.30 & 14.5 & 5.7 \\
\hline M9a1a1c & 35 & 6.14 & 1.55 & 15.9 & 4.0 & 0.97 & 0.28 & 7.8 & 2.2 & & & & & \\
\hline M9a1a1c1 & 34 & 5.21 & 1.25 & 13.5 & 3.2 & 0.94 & 0.28 & 7.5 & 2.3 & & & & & \\
\hline M9a1a1c1* (w/o M9a1a1c1b) & 9 & 3.33 & 1.03 & 8.6 & 2.7 & 1.67 & 0.94 & 13.3 & 7.5 & 67 & 0.39 & 0.14 & 7.3 & 2.6 \\
\hline M9a1a1c1b & 25 & 3.88 & 1.32 & 10.0 & 3.4 & 0.68 & 0.18 & 5.4 & 1.5 & & & & & \\
\hline M9a1a1c1b (@16291) & 24 & 2.88 & 0.94 & 7.4 & 2.4 & 0.58 & 0.18 & 4.7 & 1.4 & 170 & 0.32 & 0.08 & 6.1 & 1.5 \\
\hline M9a1a1c1b (@16291-711) & 21 & 1.90 & 0.35 & 4.9 & 0.9 & 0.48 & 0.16 & 3.8 & 1.3 & & & & & \\
\hline
\end{tabular}

${ }^{a}$ Number of mtDNA sequences.

b Using the corrected molecular clock proposed by Soares et al. [60].

c According to the recalibrated synonymous rate of Loogväli et al. [61]. The rate of Soares et al. [60] (7,884 years/synonymous substitution) was similar to Loogväli et al. [61] (7990 years/synonymous substantiation), and age estimates based on this rate were not listed in the Table.

${ }^{d}$ Using the corrected molecular clock proposed by Soares et al. [60].

e The numbers of mtDNAs refer the sequences allocated into M9a1a2 with additional back-mutation 16362.

haplogroup M9a'b might trace its origin in North Asia/ northern China $[16,25]$ or Central Asia (including Tibet) [20], evidence from entire mtDNA genomes and extensive phylogeographic analyses unanimously indicated that this haplogroup was originated in southern China and/or Southeast Asia, a vast region containing contemporary northern Vietnam and South China (that is, Guangxi, Guangdong, and Hainan). This result was consistent with the previous observation on haplogroup $\mathrm{E}$, the sister clade of M9a'b [14], and thus provided further evidence in support of the common origin of haplogroup M9 (embracing M9a'b and E) in Southeast Asia [14]. Moreover, the emergence of M9a'b and/or M9a and their related early dispersal in southern China and/or Southeast Asia (Figure 4) around 18 to 28 kya (Table 1) was in agreement with the rise of the Upper Paleolithic culture within this region (Figure $5 \mathrm{a}$ ). During this period, the first (approximately 26 to 36 kya) and second (approximately 20 to 26 kya) stages of Bailiandong culture in Guangxi [26] and the Son Vi culture (also Sonviian; approximately 13 to $23 \mathrm{kya}$ ) in northern Vietnam [27] appeared and showed tight links (for example, cobble choppers and blades) with each other [26].
Our phylogeographic analysis of haplogroup M9a'b further revealed some distinct distribution patterns of its sub-haplogroups. In particular, M9a1b and M9a1a2 showed a restricted distribution in western China, Myanmar, northeast India, and the south Himalaya region (Figure 4; see Additional file 2), but were virtually very rare or absent in northern China and Northeast Asia and even southern China (the suggested place of origin of M9a'b and M9a1), indicating that both haplogroups might have distinct origins from the other M9a'b sub-haplogroups. Meanwhile, M9a1a2 and M9a1b coincidentally shared a similar expansion age (approximately 9 to 12 kya; Table 1 ), which indicated that both haplogroups might have been involved in the same demographic event. Together, the current distribution pattern of haplogroups M9a1b and M9a1a2 was likely attributed to an inland post-glacial dispersal event, which started from southern China along with the differentiation of M9a1 (approximately 17 to 21 kya; Table 1; Figure $5 b$ ), then moved westward to western China, and finally to northeast India and the south Himalaya region (Figure 5c). Nevertheless, the phylogeographic pattern of M9a1a1 suggested some northward Late Glacial dispersal (s). In particular, the enrichment of haplogroup 


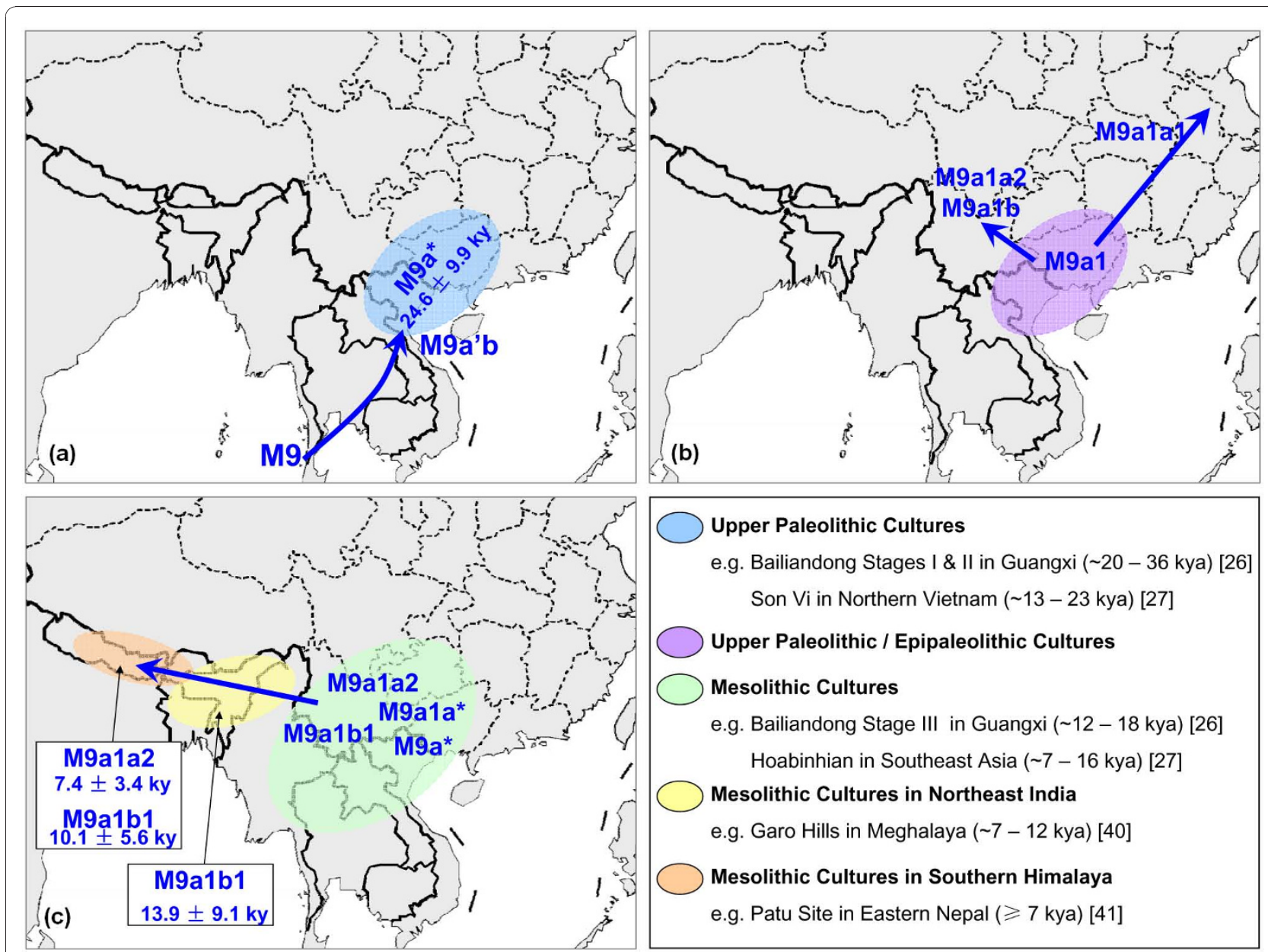

Figure 5 The putative migratory routes of M9a'b and the distribution of the potentially associated archaeological evidence. Arrows refer to the dispersal direction but do not denote precisely defined geographic routes. The ages of specific haplogroups were based on the mtDNA control region sequences: (a) M9a* lineages in southern China and Southeast Asia; (b) M9a1 in southern China; and (c) M9a1b1 lineages in northeast India, and M9a1b1 and M9a1a2 lineages in the south Himalaya region.

M9a1a1c1b in Tibet was likely to be explained by some recent local expansions, such as the Neolithic expansion $[28,29]$ in this region.

It is possible that the observed pattern based on a single haplogroup (that is, M9a'b) might be biased by genetic drift, natural selection, and later population dynamic events [30]. So we tried to look for the parallel genetic evidence from the published data: haplogroup F1c [31,32], with mtDNA control region motif as 16111-16129-16304-152-249d, was found to show a similar phylogeographic pattern with haplogroup M9a1. As previous studies had indicated that haplogroups F1 and F1a (a sister clade of F1c) probably had an origin in southern China and/or Southeast Asia [32-34], haplogroup F1c also probably originated in the same region. The network based on 108 mtDNA control region sequences (see Additional file 3) suggested that several branches derived directly from the root type of F1c, and these lineages were mainly restricted in western China, northeast India, and the south Himalaya region (Figure 6). Regardless of the major branch defined by variant 16266, the expansion time of haplogroup (paragroup) F1 $\mathrm{c}^{*}$ was estimated to be $10.2 \pm 4.1 \mathrm{kya}$. Therefore, the differentiation of haplogroup F1c* had likely witnessed certain inland post-glacial dispersal from southern China and/or southwestern China to northeast India and the south Himalaya region, which mirrored the distribution pattern of M9a1b and M9a1a2.

The proper interpretation of the obtained genetic data to reconstruct complex colonization scenarios would benefit from the incorporation of archaeological materials. After the LGM, around 12 to 15 kya, great cultural changes in South China and northern Vietnam were suggested to be associated with the prevalence of the Mesolithic culture, such as the Hoabinhian culture $[27,35]$ and the third stage of Bailiandong culture 


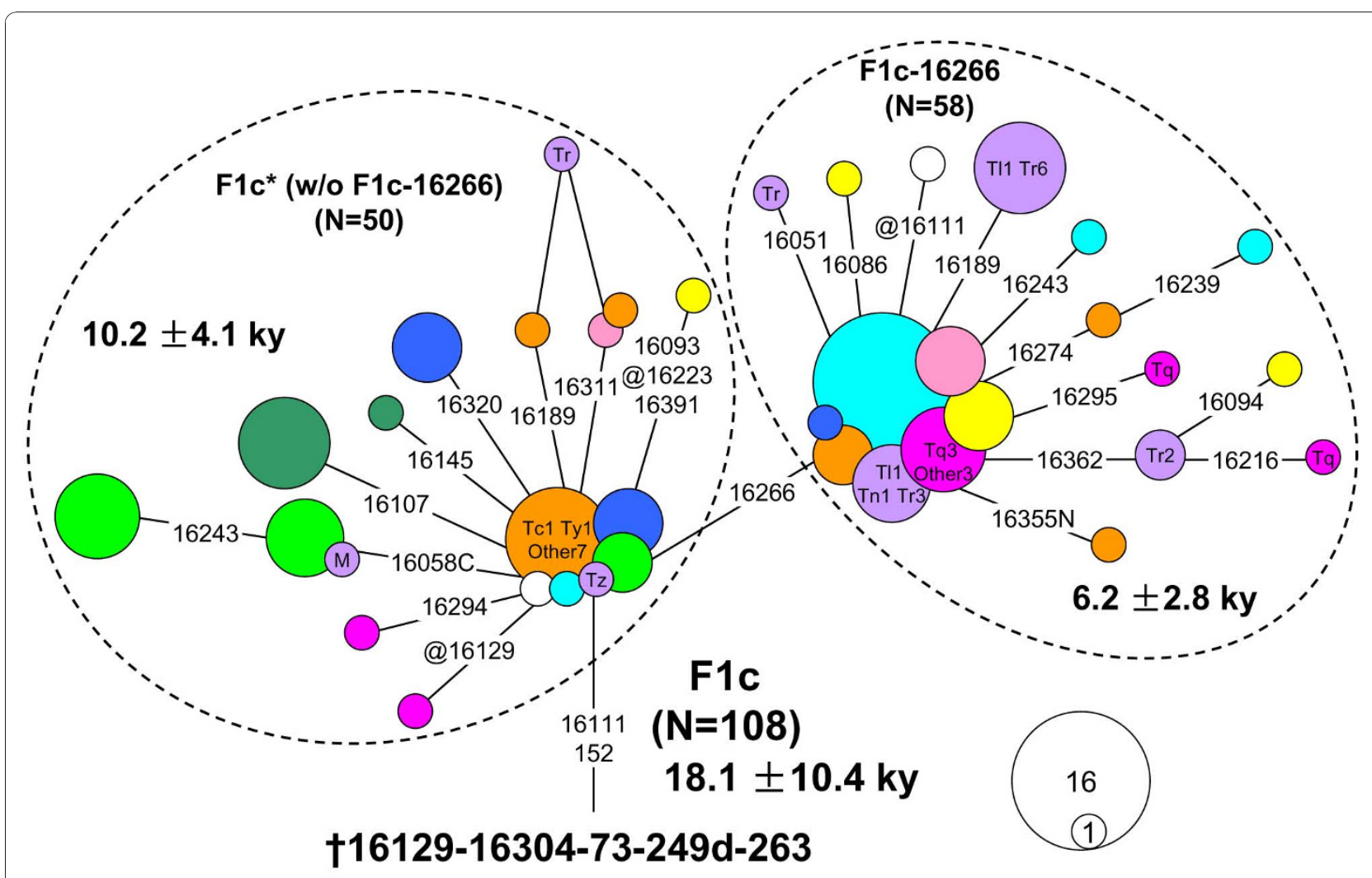

Figure 6 Median-joining network of HVS-I haplotypes observed in 108 F1c mtDNAs. All sequences were retrieved from the published data (see Additional file 3). For the information of the labels, see Figure 3 and its legend.

[26,36]. The expansions of these Mesolithic cultures in southern China and Southeast Asia were already discussed in some recent studies [37,38]. Intriguingly, the timing for our proposed inland post-glacial dispersal scenario was largely overlapped with the Mesolithic period, and more importantly, this inland route from southwestern China to northeast India and the south Himalaya region was in coincidence with the Hoabinhian links connecting southwestern China [39], northeast India [40], and Nepal [41,42] (Figure 5c). It seemed that the advanced technology (for example, pottery $[26,36,43])$ and the improved climate would be the major factors in triggering the post-glacial dispersal. However, other factors such as the dispersal of language groups and the expansion of agriculture could not be neglected completely. Considering some major branches within M9a'b were relatively concentrated in different Tibeto-Burman and Khasi-Khmuic populations (see Additional file 1), the dispersals of Tibeto-Burman [44] and Austro-Asiatic populations [45], together with the intergroup genetic admixture [45], were likely to shape the current distribution pattern of M9a'b. Further work on more genetic markers (for example, NRY, genomewide single nucleotide polymorphisms, and even ancient
DNA) with extensive sampling will be required to further confirm our speculation regarding the prehistoric peopling scenario(s) in East Asia.

\section{Conclusions}

Our comprehensive phylogeographic analyses of mtDNA haplogroup M9a'b revealed that southern China and/or Southeast Asia served as a source of the post-LGM dispersal in East Asia. Most importantly, our results provided the first direct genetic evidence in support of the existence of an inland dispersal in mainland East Asia from southern China, through western China, to northeast India and the south Himalaya region. This dispersal was likely triggered by the improved climate and the advanced Mesolithic culture, and had played important roles in shaping the matrilineal gene pool of modern East Asians.

\section{Methods}

\section{Subjects}

A total of 837 candidate M9a'b mtDNA samples (583 from the literature and 254 from this study; see Additional file 1), with specific mtDNA control region motif 16223-16234-16362-153 and/or coding region diagnostic 
site 3394 or 4491, were pinpointed from over 28,000 subjects residing across East Eurasia (Figure 1; see Additional file 2). All subjects recruited in this study were interviewed with informed consent to ascertain their ethnic affiliations. To better understand the phylogeny within M9a'b, besides the 61 published M9a'b mtDNA genome sequences that were retrieved from the literature and GenBank (see Additional file 4), an additional 59 representatives were selected from our own samples for complete mtDNA sequencing, with a special attempt to cover the widest range of internal variation within the haplogroup [46]. By virtue of the updated phylogeny of haplogroup M9a'b, we further classified the remaining M9a'b candidates based on the specific coding region motifs (for our own samples; see Additional file 1) and/ or by matching and near-matching $[32,47]$ with the well-defined M9a'b lineages (for the reported mtDNAs from the literature). Using this strategy, the vast majority of the M9a'b mtDNA samples (771/837) could be unambiguously allocated into specific sub-haplogroups within M9a'b, whereas the remaining 66 sequences (all from the literature) could only be roughly assigned into M9a'b* due to lack of further information (see Additional file 1).

\section{Sequence analysis}

The sequencing protocol and phylogeny reconstruction were performed as fully described before $[48,49]$, and some caveats for data quality-control were followed during the data generation and handling [50,51]. Sequences were edited and aligned by using Lasergene (DNAStar Inc., Madison, Wisconsin, USA) and variations were scored relative to the revised Cambridge Reference Sequence (rCRS) [52]. For the C-stretch length variants in the control region, we followed the rules proposed by Bandelt and Parson [53]. The transition at 16519 and the C-length polymorphisms in regions 16180 to 16193 and 303 to 315 were disregarded in the analyses. The classification of the variants of each mtDNA genomes was performed with mtDNA GeneSyn $1.0 \mathrm{http}: / /$ www. ipatimup.pt/downloads/mtDNAGeneSyn.zip [54] and MitoTool http://mitotool.org/index.html [55]. Sequences generated in this study have been deposited in GenBank (Accession Nos. GQ337542, GQ337575, GQ337588, and HM346881 to HM346936).

\section{Phylogenetic tree construction and data analysis}

The phylogenetic tree of $120 \mathrm{M} 9 \mathrm{a}$ 'b complete mtDNA sequences was reconstructed manually and checked by NETWORK 4.516 http://www.fluxus-engineering.com/ sharenet.htm. For the HVS data and/or partial coding region, the median-joining network of 837 M9a'b mtDNA sequences was constructed manually and was further checked by using the Network 4.516 [56]. The counter maps of spatial frequencies [57] were constructed to elaborate the geographic distribution patterns of haplogroup M9a'b and its sub-haplogroups using the Kriging algorithm of Surfer 8.0 (Golden Software Inc. Golden, Colorado, USA).

The average sequence divergence ( $\rho$ ) of the haplotypes to their most recent common ancestor, accompanied by a heuristic estimate of the standard error $(\sigma)$, was calculated as fully described before $[58,59]$. Then, the $\rho \pm \sigma$ value was converted into the coalescent age for certain haplogroup by using the most recently proposed calibration rates for mtDNA mutations [60] and only synonymous substitutions [61], respectively. For the control region, we adopted the rate of 18,845 years per transition between 16090 and 16365 [60].

\section{Additional material}

Additional file 1: List of M9a'b mtDNAs identified in East Eurasians. This is an EXCEL file describing the information of 837 M9a'b mtDNAs.

Additional file 2: Population distribution of haplogroup $\mathbf{M} 9 \mathbf{a}^{\prime} \mathbf{b}$. This is an EXCEL file providing information includes sample sizes, geographic locations and distributions of sub-haplogroups.

Additional file 3: List of F1c lineages identified from the published data. This is an EXCEL file describing the information of 108 F1C mtDNAs.

Additional file 4: List of M9a'b complete sequences that were included in Figure 2. This is a DOC file describing the information of 120 complete M9a'b mtDNA genomes and the references for all additional files.

\section{Abbreviations}

HVS: hypervariable segment; kya: kilo-years ago; LGM: Last Glacial Maximum; mtDNA: mitochondrial DNA; NRY: non-recombining region of $Y$ -

chromosome; rCRS: revised Cambridge Reference Sequence.

\section{Acknowledgements}

We thank all participants involved in this study. We also thank Chun-Ling Zhu, Shi-Fang Wu, Jun-Dong He, Shi-Kang Gou, Feng Gao, Nguyen Ngoc Sang, and Ji-Shan Wang for their technical assistance. We thank Dr. Mannis van Oven for the discussion about the nomenclature of mtDNA

haplogroups. This study was supported by grants from the National Natural Science Foundation of China (30621092 and 30900797), and the Bureau of Science and Technology of Yunnan Province (2009Cl119).

\section{Author details}

${ }^{1}$ State Key Laboratory of Genetic Resources and Evolution, Kunming Institute of Zoology, Chinese Academy of Sciences, Kunming, China. ${ }^{2}$ KIZ/CUHK Joint Laboratory of Bioresources and Molecular Research in Common Diseases, Kunming, China. ${ }^{3}$ Laboratory for Conservation and Utilization of Bioresources, Yunnan University, Kunming, China. ${ }^{4}$ Key Laboratory of Animal Models and Human Disease Mechanisms of the Chinese Academy of Sciences \& Yunnan Province, Kunming Institute of Zoology, Kunming, China. ${ }^{5}$ Cellular Immunology Laboratory, Department of Zoology, University of North Bengal, Siliguri, India. ${ }^{6}$ Graduate School of the Chinese Academy of Sciences, Beijing, China.

\section{Authors' contributions}

MSP, MGP, BM, YTC, MZ, JL, HWW, HP, WZW, AMZ, WZ, DW, YZ, YY, and TKC performed the experiments. MSP, YGY, and QPK analyzed the data. MSP, QPK, and YPZ conceived and designed the experiments. MSP, YGY, QPK, and YPZ wrote the paper. All authors read and approved the final manuscript. 
Received: 13 October 2010 Accepted: 10 January 2011

Published: 10 January 2011

\section{References}

1. Clark PU, Dyke AS, Shakun JD, Carlson AE, Clark J, Wohlfarth B, Mitrovica JX, Hostetler SW, McCabe AM: The Last Glacial Maximum. Science 2009 325:710-714

2. Forster P: Ice Ages and the mitochondrial DNA chronology of human dispersals: a review. Philos Trans R Soc Lond B Biol Sci 2004, 359:255-264.

3. Barton LW, Brantingham PJ, Ji D: Late Pleistocene climate change and Paleolithic cultural evolution in northern China: implications from the Last Glacial Maximum. In Late Quaternary Climate Change and Human Adaptation in Arid China. Volume 9. Edited by: Madsen DB, Chen F, Gao X. Amsterdam: Elsevier; 2007:105-128, (van der Meer J (Series Editor): Developments in Quaternary Science).

4. Xu PF, Yan WM, Wang YP, Zhang ZP, Shao WP, Chang KC, Lu LC, Xu H, Wang RX: The Formation of Chinese Civilization: An Archaeological Perspective. Beijing, New Haven/London: New World Press, Yale University Press; 2004.

5. Chen S: Environment adaptation and diffusion of North China humans in Late Pleistocene. Quaternary Sci 2006, 26:522-533.

6. Xing G, Yuan BY, Pei SW, Wang HM, Chen FY, Feng XW: Analysis of sedimentary-geomorphologic variation and the living environment of hominids at the Shuidonggou Paleolithic site. Chin Sci Bull 2008 53:2025-2032.

7. Ji D, Chen F, Betinnger RL, Elson RG, Geng Z, Barton L, Wang H, An C, Zhang D: Human response to the Last Glacial Maximum: evidence from North China. Acta Anthropol Sin 2005, 24:270-282.

8. Goebel T: The "Microblade Adaptation" and recolonization of Siberia during the Late Upper Pleistocene. Archeological Papers of the American Anthropological Association 2002, 12:117-131.

9. Underhill PA, Kivisild T: Use of Y chromosome and mitochondrial DNA population structure in tracing human migrations. Annu Rev Genet 2007 41:539-564.

10. Renfrew C: Archaeogenetics - towards a 'new synthesis'? Curr Biol 2010 20:R162-165

11. Soares P, Achilli A, Semino O, Davies W, Macaulay V, Bandelt HJ, Torroni A Richards MB: The archaeogenetics of Europe. Curr Biol 2010, 20:R174-R183.

12. Černý $V$, Mulligan CJ, Fernandes $V$, Silva NM, Alshamali F, Nourdin Harich AN, Cherni L, El Gaaied AB, Al-Meeri A, Pereira L: Internal diversification of mitochondrial haplogroup R0a reveals post-Last Glacial Maximum demographic expansions in South Arabia. Mol Biol Evol 2011, 28:71-78.

13. Kumar S, Padmanabham PB, Ravuri RR, Uttaravalli K, Koneru P, Mukherjee PA, Das B, Kotal M, Xaviour D, Saheb SY, Rao VR: The earliest settlers' antiquity and evolutionary history of Indian populations: evidence from M2 mtDNA lineage. BMC Evol Biol 2008, 8:230.

14. Soares P, Trejaut JA, Loo JH, Hill C, Mormina M, Lee CL, Chen YM, Hudjashov G, Forster P, Macaulay V, Bulbeck D, Oppenheimer S, Lin M, Richards MB: Climate change and postglacial human dispersals in Southeast Asia. Mol Biol Evol 2008, 25:1209-1218.

15. Zhao M, Kong QP, Wang HW, Peng MS, Xie XD, Wang WZ, Duan JG, Cai MC, Zhao SN, Tu YQ, Wu SF, Yao YG, Bandelt HJ, Zhang YP: Mitochondrial genome evidence reveals successful Late Paleolithic settlement on the Tibetan Plateau. Proc Natl Acad Sci USA 2009, 106:21230-21235.

16. Qin Z, Yang Y, Kang L, Yan S, Cho K, Cai X, Lu Y, Zheng H, Zhu D, Fei D, Li S, Jin L, Li H, Genographic Consortium: A mitochondrial revelation of early human migrations to the Tibetan Plateau before and after the last glacial maximum. Am J Phys Anthropol 2010, 143:555-569.

17. Fornarino S, Pala M, Battaglia V, Maranta R, Achilli A, Modiano G, Torroni A, Semino O, Santachiara-Benerecetti SA: Mitochondrial and Y-chromosome diversity of the Tharus (Nepal): a reservoir of genetic variation. BMC Evol Biol 2009, 9:154

18. Chandrasekar A, Kumar S, Sreenath J, Sarkar BN, Urade BP, Mallick S, Bandopadhyay SS, Barua P, Barik SS, Basu D, Kiran U, Gangopadhyay P, Sahani R, Prasad BV, Gangopadhyay S, Lakshmi GR, Ravuri RR, Padmaja K, Venugopal PN, Sharma MB, Rao VR: Updating phylogeny of mitochondrial DNA macrohaplogroup $M$ in India: dispersal of modern human in South Asian corridor. PLOS ONE 2009, 4:e7447.
19. Reddy BM, Langstieh BT, Kumar $V$, Nagaraja T, Reddy ANS, Meka A, Reddy AG, Thangaraj K, Singh L: Austro-Asiatic tribes of Northeast India provide hitherto missing genetic link between South and Southeast Asia. PLOS ONE 2007, 2:e1141.

20. Tanaka M, Cabrera VM, González AM, Larruga JM, Takeyasu T, Fuku N, Guo LJ, Hirose R, Fujita Y, Kurata M, Shinoda K, Umetsu K, Yamada Y, Oshida Y, Sato Y, Hattori N, Mizuno Y, Arai Y, Hirose N, Ohta S, Ogawa O, Tanaka Y, Kawamori R, Shamoto-Nagai M, Maruyama W, Shimokata H, Suzuki R, Shimodaira H: Mitochondrial genome variation in Eastern Asia and the peopling of Japan. Genome Res 2004, 14:1832-1850.

21. Kong QP, Bandelt HJ, Sun C, Yao YG, Salas A, Achilli A, Wang CY, Zhong L, Zhu CL, Wu SF, Torroni A, Zhang YP: Updating the East Asian mtDNA phylogeny: a prerequisite for the identification of pathogenic mutations. Hum Mol Genet 2006, 15:2076-2086.

22. van Oven $M$, Kayser $M$ : Updated comprehensive phylogenetic tree of global human mitochondrial DNA variation. Hum Mutat 2009, 30:E386-E394.

23. Cox MP: Accuracy of molecular dating with the rho statistic: deviations from coalescent expectations under a range of demographic models. Hum Biol 2008, 80:335-357

24. Endicott P, Ho SY, Metspalu M, Stringer C: Evaluating the mitochondrial timescale of human evolution. Trends Ecol Evol 2009, 24:515-521.

25. Xue F, Wang Y, Xu S, Zhang F, Wen B, Wu X, Lu M, Deka R, Qian J, Jin L: A spatial analysis of genetic structure of human populations in China reveals distinct difference between maternal and paternal lineages. Eur $J$ Hum Genet 2008, 16:705-717.

26. Guangxi Liuzhou Science Museum of Bailiandong Lava-Caves (Ed.): . Bailiandong in Liuzhou Beijing: Science Press; 2009.

27. Ha VT: The Hoabinhian and before. Bull IPPA 1997, 16:35-41.

28. Su B, Xiao CJ, Deka R, Seielstad MT, Kangwanpong D, Xiao JH, Lu DR, Underhill P, Cavalli-Sforza L, Chakraborty RJ, Jin L: Y chromosome haplotypes reveal prehistorical migrations to the Himalayas. Hum Genet $2000,107 \cdot 582-590$

29. Gayden T, Cadenas AM, Regueiro M, Singh NB, Zhivotovsky LA, Underhill PA, Cavalli-Sforza LL, Herrera RJ: The Himalayas as a directional barrier to gene flow. Am J Hum Genet 2007, 80:884-894.

30. Balloux F, Handley LL, Jombart T, Liu H, Manica A: Climate shaped the worldwide distribution of human mitochondrial DNA sequence variation. Proc Biol Sci 2009, 276:3447-3455.

31. Kivisild T, Tolk HV, Parik J, Wang YM, Papiha SS, Bandelt HJ, Villems R: The emerging limbs and twigs of the East Asian mtDNA tree. Mol Biol Evol $2002,19 \cdot 1737-1751$.

32. Yao YG, Kong QP, Bandelt HJ, Kivisild T, Zhang YP: Phylogeographic differentiation of mitochondrial DNA in Han Chinese. Am J Hum Genet 2002, 70:635-651

33. Ballinger SW, Schurr TG, Torroni A, Gan YY, Hodge JA, Hassan $\mathrm{K}$, Chen $\mathrm{KH}$, Wallace DC: Southeast Asian mitochondrial DNA analysis reveals genetic continuity of ancient mongoloid migrations. Genetics 1992, 130:139-152.

34. Torroni A, Miller JA, Moore LG, Zamudio S, Zhuang J, Droma T, Wallace DC: Mitochondrial DNA analysis in Tibet: implications for the origin of the Tibetan population and its adaptation to high altitude. Am J Phys Anthropol 1994, 93:189-199.

35. Gorman C: The Hoabinhian and after: subsistence patterns in Southeast Asia during the late Pleistocene and early recent periods. World Archaeol 1971, 2:300-320.

36. Tong EZ, Hutterer KL: The Mesolithic period in South China and Southeast Asia. In Southern Civilization. Edited by: Tong EZ. Chongqing: Chongqing Publishing House; 2004:58-87.

37. Hill C, Soares P, Mormina M, Macaulay V, Meehan W, Blackburn J, Clarke D, Raja JM, Ismail P, Bulbeck D, Oppenheimer S, Richards M: Phylogeography and ethnogenesis of aboriginal Southeast Asians. Mol Biol Evol 2006, 23:2480-2491.

38. Karafet TM, Hallmark B, Cox MP, Sudoyo H, Downey S, Lansing JS, Hammer MF: Major east-west division underlies Y chromosome stratification across Indonesia. Mol Biol Evol 2010, 27:1833-1844.

39. Gao F: Excavation of remains from Nanminan cave sites, Jinghong. In Exploring Historical Footprints, Protecting Cultural Relics: In Memory of the 50th Anniversary of Yunnan Provincial Institute of Cultural Relics and Archaeology. Edited by: the Yunnan Provincial Institute of Cultural Relics and Archaeology. Kunming: Yunnan Publishing Group. Kunming: Yunnan Publishing Group, Yunnan Education Publishing House; 2009:31-34. 
40. Sharma HC: Prehistoric archaeology of the North-East. In The Anthropology of North-East India. Edited by: Subba TB, Ghosh GC. New Delhi: Orient Longman Private Limited; 2003:11-30.

41. Corvinus G: The prehistory of Nepal after 10 years of research. Bull IPPA 1996, 14:43-55.

42. Zöller L: Chronology of upper Pleistocene "red silts" in the Siwalik system and constraints for the timing of the upper palaeolithic in Nepal. Catena 2000, 41:229-235.

43. Boaretto E, Wu X, Yuan J, Bar-Yosef O, Chu V, Pan Y, Liu K, Cohen D, Jiao T, Li S, Gu H, Goldberg P, Weiner S: Radiocarbon dating of charcoal and bone collagen associated with early pottery at Yuchanyan Cave, Hunan Province, China. Proc Natl Acad Sci USA 2009, 106:9595-9600.

44. van Driem G: Tibeto-Burman vs Indo-Chinese: implications for population geneticists, archaeologists and prehistorians. In The Peopling of East Asia : Putting Together Archaeology, Linguistics and Genetics. Edited by: Sagart L, Blench R, Sanchez-Mazas A. London and New York: RoutledgeCurzon; 2005:81-106

45. Chaubey G, Metspalu M, Choi Y, Magi R, Romero IG, Soares P, van Oven M, Behar DM, Rootsi S, Hudjashov G, Mallick CB, Karmin M, Nelis M, Parik J, Reddy AG, Metspalu E, van Driem G, Xue Y, Tyler-Smith C, Thangaraj K, Singh L, Remm M, Richards MB, Lahr MM, Kayser M, Villems R, Kivisild T: Population genetic structure in Indian Austroasiatic speakers: the role of landscape barriers and sex-specific admixture. Mol Biol Evol.

46. Achilli A, Rengo C, Magri C, Battaglia V, Olivieri A, Scozzari R, Cruciani F, Zeviani M, Briem E, Carelli V, Moral P, Dugoujon JM, Roostalu U, Loogväli EL, Kivisild T, Bandelt HJ, Richards M, Villems R, Santachiara-Benerecetti AS, Semino O, Torroni A: The molecular dissection of mtDNA haplogroup $\mathrm{H}$ confirms that the Franco-Cantabrian glacial refuge was a major source for the European gene pool. Am J Hum Genet 2004, 75:910-918.

47. Yao YG, Kong QP, Wang CY, Zhu CL, Zhang YP: Different matrilineal contributions to genetic structure of ethnic groups in the Silk Road region in China. Mol Biol Evol 2004, 21:2265-2280.

48. Wang HW, Jia XY, Ji YL, Kong QP, Zhang QJ, Yao YG, Zhang YP: Strikingly different penetrance of LHON in two Chinese families with primary mutation G11778A is independent of mtDNA haplogroup background and secondary mutation G13708A. Mutat Res 2008, 643:48-53.

49. Fendt L, Zimmermann B, Daniaux M, Parson W: Sequencing strategy for the whole mitochondrial genome resulting in high quality sequences. BMC Genomics 2009, 10:139.

50. Kong QP, Salas A, Sun C, Fuku N, Tanaka M, Zhong L, Wang CY, Yao YG, Bandelt $\mathrm{HJ}$ : Distilling artificial recombinants from large sets of complete mtDNA genomes. PLOS ONE 2008, 3:e3016.

51. Yao YG, Salas A, Logan I, Bandelt HJ: mtDNA data mining in GenBank needs surveying. Am J Hum Genet 2009, 85:929-933.

52. Andrews RM, Kubacka I, Chinnery PF, Lightowlers RN, Turnbull DM, Howell N: Reanalysis and revision of the Cambridge reference sequence for human mitochondrial DNA. Nat Genet 1999, 23:147.

53. Bandelt $H J$, Parson W: Consistent treatment of length variants in the human mtDNA control region: a reappraisal. Int J Legal Med 2008 122:11-21

54. Pereira L, Freitas F, Fernandes V, Pereira JB, Costa MD, Costa S, Maximo V, Macaulay $V$, Rocha R, Samuels DC: The diversity present in 5140 human mitochondrial genomes. Am J Hum Genet 2009, 84:628-640.

55. Fan L, Yao YG: MitoTool: a web server for the analysis and retrieval of human mitochondrial DNA sequence variations. Mitochondrion 2010

56. Bandelt $H J$, Forster $P$, Röhl A: Median-joining networks for inferring intraspecific phylogenies. Mol Biol Evol 1999, 16:37-48.

57. Cavalli-Sforza LL, Menozzi P, Piazza A: The History and Geography of Human Genes. Princeton: Princeton University Press; 1994.

58. Forster $\mathrm{P}$, Harding R, Torroni A, Bandelt HJ: Origin and evolution of native American mtDNA variation: a reappraisal. Am J Hum Genet 1996, 59:935-945.

59. Saillard J, Forster P, Lynnerup N, Bandelt HJ, Norby S: mtDNA variation among Greenland Eskimos: the edge of the Beringian expansion. Am J Hum Genet 2000, 67:718-726.

60. Soares P, Ermini L, Thomson N, Mormina M, Rito T, Röhl A, Salas A, Oppenheimer S, Macaulay V, Richards MB: Correcting for purifying selection: an improved human mitochondrial molecular clock. Am J Hum Genet 2009, 84:740-759.

61. Loogväli EL, Kivisild T, Margus T, Villems R: Explaining the imperfection of the molecular clock of hominid mitochondria. PLOS ONE 2009, 4:e8260
62. Ji Y, Zhang AM, Jia X, Zhang YP, Xiao X, Li S, Guo X, Bandelt HJ, Zhang Q, Yao YG: Mitochondrial DNA haplogroups M7b1'2 and M8a affect clinical expression of leber hereditary optic neuropathy in Chinese families with the m.11778G-> A mutation. Am J Hum Genet 2008, 83:760-768.

doi:10.1186/1741-7007-9-2

Cite this article as: Peng et al:: Inland post-glacial dispersal in East Asia revealed by mitochondrial haplogroup M9a'b. BMC Biology 2011 9:2.

\section{Submit your next manuscript to BioMed Central and take full advantage of:}

- Convenient online submission

- Thorough peer review

- No space constraints or color figure charges

- Immediate publication on acceptance

- Inclusion in PubMed, CAS, Scopus and Google Scholar

- Research which is freely available for redistribution

Submit your manuscript at www.biomedcentral.com/submit 